\title{
Ureteric Lesions Detected in Normally Functioning Kidney Allografts: Risk Factors and Clinical Implications
}

\author{
A.J. Figueiredo, M.X. Cunha, A.F. Mota, and A.L. Furtado
}

\begin{abstract}
Introduction. We characterized the alterations in ureteral biopsies from normally functioning kidney allografts to study risk factors.

Materials and methods. We studied 55 ureteral fragments from kidney grafts obtained during cystoscopy for routine double-J stent extraction. We evaluated the type and severity of the lesions, the risk factors for their occurrence, and their relation to the evolution of the transplant, including the occurrence of renal rejection episodes or ureteral complications.

Results. Borderline or rejection lesions were detected in 21 of the 55 fragments. Rejection lesions were more common among biopsies performed in the first 80 days (54.6\%) than during the 120 days afterward $(15.4 \%, P=.043)$. Similarly, urothelium reactivity was detected in $71.4 \%$ and $30.7 \%$ of the biopsies performed up to and after 4 months, respectively $(P=.008)$. Urothelial atrophy was detected in $20 \%$ of the fragments, the age of the donors being higher in these cases $(P=.026)$. There was a trend to the association of borderline or rejection lesions in the ureteral biopsies and a history of an acute renal rejection episode $(P=.053)$. There were no detectable relations between those findings and the evolution of the transplant.

Conclusions. Thirty-eight percent of the biopsed ureters showed rejection or borderline lesions, these lesions were more common among biopsies done in the first months after transplantation. These findings are similar to the ones found in routine renal biopsies. We did not find any significant relation between the nature of the lesions encountered on the ureteral biopsies and the evolution of the transplant.
\end{abstract}

$\mathrm{D}$ ESPITE THE EXTENSIVE experience in renal transplantation, there are few studies on lesions that may occur in the ureteral segment of the renal graft. Furthermore, the existing publications evaluated ureters from excised nonfunctioning grafts ${ }^{1}$ or from grafts that developed ureteral stenoses or fistulae. ${ }^{2,3}$ Herein we characterized the alterations present in ureteral biopsies taken from normal functioning kidney allografts.

\section{MATERIAL AND METHODS}

We studied 55 ureteral fragments taken from normal functioning kidney allografts. The study material was obtained during cystoscopy performed for another reason, namely in 53 cases for removal of the "double-J" stent that had been placed at transplant surgery. We biopsied the graft ureteral neomeatus with a grasp forceps. All procedures were performed with informed consent, under topical anesthesia, and only when well tolerated. Patients included 34 men and 21 women of mean age $40.44 \pm 12.35$ years (17 to 66 years). Donor age was $30.64 \pm 12.37$ years. Transplants were from cadaveric donors in 53 cases, the cause of death being brain trauma in 43 cases and brain stroke in 10 cases. The mean mechanical ventilation time was $68.48 \pm 66.65$ hours ( 8 to 288 hours). Dialysis time of the recipients was $31.04 \pm 24.14$ months ( 5 to 107 months). Human leukocyte antigen (HLA) compatibilities were $2.98 \pm 0.91$ ( 1 to 6$)$ and graft cold ischemia time was $19.70 \pm 6.72$ hours ( 2 to 39 hours). Mean interval between transplant and biopsy was 103.02 \pm 47.75 days ( 15 to 320 days); the vast majority $(86 \%)$ of the biopsies being performed between 2 and 4 months after transplant. The mean follow-up time of the patients after transplant was 33.81 \pm 14.63 months (12 to 55 months). All fragments were fixed in formalin and stained with eosin-hematoxylin, CD3, CD4, CD8,

From the Department of Urology and Renal Transplantation, Coimbra University Hospital, Coimbra, Portugal.

Address reprint requests to Arnaldo J.C. Figueiredo, Department of Urology and Renal Transplantation, Coimbra University Hospital, 3049 Coimbra Codex, Portugal. E-mail: ajcfigueiredo@ netcabo.pt 
and, when justified, Masson trichrome and Martinotti stain. We evaluated the cellular infiltration of the urothelium, chorion, and muscular layer, characterizing their grade and type and registering the presence of urothelial vacuolization, exfoliation, atrophy, and reactivity and chorion edema or fibrosis. Taking into consideration the criteria used to classify transplant lesions, primarily of the kidney ${ }^{4}$ but also of other organs, ${ }^{5,6}$ we developed criteria for ureteral acute (AR) or chronic rejection. We analyzed the risk factors for the lesions detected based upon donor, recipient, and transplant criteria and their relation with the evolution of the transplant, including the occurrence of renal rejection episodes or ureteral complications. In 27 cases, ureteral fragments were obtained at transplant surgery at 10 to 15 minutes after graft reperfusion, allowing us to compare our results with these findings. The Student $t$ test, ANOVA test, and $\chi^{2}$ test were used for statistical comparisons. For all tests, a $P$ value $<.05$ was considered significant.

\section{RESULTS}

There were no significant complications from the biopsies, apart from a case of hematuria that needed bladder cathe- terization for clot evacuation. All fragments were adequate for histological study, despite the absence of muscular tissue in 20 cases. Urothelial infiltration by $\mathrm{CD}^{+} \mathrm{T}$ lymphocytes was detected in $45(82 \%)$ cases and were mild in 29 cases. All fragments revealed abnormal cellular infiltration of the chorion; $\mathrm{CD}^{+} \mathrm{T}$ lymphocytes were the predominant subtype in 34 (62\%) cases. B lymphocytes, which were detected less often, were always associated with $\mathrm{T}$ lymphocytes. As a whole, borderline or rejection lesions were detected in $21(38 \%)$ of the 55 fragments: namely, borderline lesions in nine cases and AR grades 1, 2, and 3 in three, seven, and two cases, respectively. Urothelial reactivity, vacuolization, atrophy, and exfoliation were detected in 34, 55, 11, and 27 cases, respectively. Chorion edema and fibrosis was detected in 54 and 28 cases, respectively.

No relation was detected between any donor or recipient factor, but there was a trend toward lower recipient age among borderline or AR cases (Table 1). Rejection lesions were absent from patients undergoing quadruple induction

Table 1. Risk Factors for the Occurrence of Alterations Suggestive of Borderline or Acute Rejection Lesions

\begin{tabular}{|c|c|c|c|}
\hline & $\begin{array}{l}\text { Reactive lesions } \\
\quad(n=34)\end{array}$ & $\begin{array}{l}\text { Borderline or AR lesions } \\
\qquad(n=21)\end{array}$ & $P$ \\
\hline Donor age (years) & $31.26 \pm 12.67$ & $29.62 \pm 12.12$ & NS \\
\hline Cadaveric donor mechanical ventilation time (hours, $n=53$ ) & $67.94 \pm 64.37$ & $69.20 \pm 71.97$ & NS \\
\hline Cold ischemia time (hours) & $19.51 \pm 6.97$ & $20.02 \pm 6.45$ & NS \\
\hline Recipient age (years) & $42.65 \pm 13.12$ & $36.86 \pm 10.07$ & NS $§$ \\
\hline Dialysis time (months) & $28.56 \pm 22.87$ & $35.05 \pm 26.12$ & NS \\
\hline HLA compatibilities $(n)$ & $3.09 \pm 1.03$ & $2.81 \pm 0.68$ & NS \\
\hline \multicolumn{4}{|l|}{ Cadaveric donor cause of death } \\
\hline Brain trauma & 26 & 17 & NS \\
\hline Brain stroke & 7 & 3 & \\
\hline \multicolumn{4}{|l|}{ Recipient associated pathology } \\
\hline No & 24 & 12 & NS \\
\hline Yes & 10 & 9 & \\
\hline \multicolumn{4}{|l|}{ Duration of transplant surgery } \\
\hline$<3$ hours & 28 & 20 & NS \\
\hline$\geq 3$ hours & 6 & 1 & \\
\hline \multicolumn{4}{|l|}{ Induction imunossupression } \\
\hline Azathioprine + steroids + cyclosporine & 4 & 2 & .027 \\
\hline MMP + steroids + cyclosporine & 20 & 14 & \\
\hline AntilL2 + MMF + steroids + cyclosporine ${ }^{*}$ & 7 & - & \\
\hline MMP + steroids + tacrolimus $^{\dagger}$ & 1 & 5 & \\
\hline Sirolimus + steroids + cyclosporine & 2 & - & \\
\hline \multicolumn{4}{|l|}{ Renal AR close to the time of ureteral biopsy } \\
\hline No & 32 & 16 & NS" \\
\hline Yes & 2 & 5 & \\
\hline \multicolumn{4}{|l|}{ Timing of the ureteral biopsy } \\
\hline Up to 80 days after transplant ${ }^{\ddagger}$ & 5 & 6 & NS \\
\hline 81 to 120 days after transplant & 18 & 13 & \\
\hline More than 121 days after transplant ${ }^{\ddagger}$ & 11 & 2 & \\
\hline \multicolumn{4}{|l|}{ Delayed graft function } \\
\hline No & 30 & 19 & NS \\
\hline Yes & 4 & 2 & \\
\hline
\end{tabular}

MMP, mycophenolate mofetil; AntilL2, daclizumab or basiliximab; AR, acute rejection.

${ }^{*}$ Difference for total; $P=.026$.

${ }^{\dagger}$ Difference for total; $P=.016$.

${ }^{\ddagger}$ Difference between the two groups; $P=.043$.

$\S P=.073$.

$\|_{P}=.053$. 
therapy including daclizumab or basiliximab, and more common with mycophenolate mofetil + methylprednisolone + tacrolimus (Table 1). Rejection lesions were more common in the biopsies performed in the first 80 days $(54.6 \%)$ than after 120 days $(15.4 \%, P=.043$; Table 1$)$. Similarly, urothelial reactivity was detected in $71.4 \%$ and $30.7 \%$ of the biopsies performed up to and after 4 months, respectively $(P=.008)$. Urothelial atrophy was detected in $20 \%$ of fragments; the age of the donors was higher in these cases $(38.00 \pm 11.38$ years vs $28.80 \pm 12.03$ years, $P=.026)$. There was a trend toward the association of borderline or rejection lesions in the ureteral biopsies and a history of acute renal rejection episodes (Table 1). There was no detectable relation between these findings and the evolution of the transplant (Table 2). We did not detect any statistically significant relations between the findings in the 27 cases where fragments were obtained during transplantation, and afterward. However, six $(35 \%)$ of the 17 cases that presented urothelial vacuolization on the first biopsy showed urothelial atrophy later, compared to only one (10\%) among the 10 cases without vacuolization $(P=.148)$. The only two cases that had important cellular infiltration of the chorion in the first biopsy tended to develop subsequent fibrosis $(P=.157)$.

\section{DISCUSSION}

The absence of studies on transplant ureteral lesions limits the accuracy and validity of their interpretation. In this study, we found borderline or AR lesions in 21 (38.2\%) of the biopsies studied. This high value, plus the apparent lack of significant relation to HLA compatibilities, renal AR episodes, and evolution of the transplant might raise the question of the adequacy of the histological diagnosis. However, several authors reported a similar high frequency of subclinical borderline or AR lesions in early renal biopsies, which did not correlate with HLA compatibilities, clinical AR episodes, or serum creatinine value. ${ }^{7,8}$ Furthermore, the prognostic significance of the finding of subclinical rejection lesions on routine renal biopsies is not well established. ${ }^{7,9}$ The detection of borderline or AR lesions mostly in early biopsies, with a decline afterward, is also observed on routine renal biopsies. ${ }^{7,8,10}$ The low incidence of ureteral complications, with two of the fistulae having occurred before the biopsy date, may justify the absence of any significant correlation. The absence of relation between the findings in these biopsies and those done at the time of transplantation is somewhat unexpected. However, the fact that the two cases that had important cellular infiltration of the chorion in the first biopsy developed fibrosis is consistent with the findings of Abo-Zenah et al on the kidney. ${ }^{11}$

In conclusion, $38 \%$ of the biopsed ureters showed rejection or borderline lesions. The lesions were more common in the biopsies done in the first months after transplanta-
Table 2. Relation Between Ureteral Lesions and Evolution of the Transplant

\begin{tabular}{lccc}
\hline & $\begin{array}{c}\text { Reactive } \\
\text { lesions }\end{array}$ & $\begin{array}{c}\text { Borderline or } \\
\text { AR lesions }\end{array}$ & $P$ \\
\hline Renal AR $(n=55)$ & 30 & 14 & $\mathrm{NS}^{+}$ \\
$\quad$ No & 4 & 7 & \\
$\quad$ Yes & & & \\
Chronic graft dysfunction $(n=53)^{*}$ & 25 & 19 & $\mathrm{NS}$ \\
$\quad$ No & 7 & 2 & \\
$\quad$ Yes & & & \\
Creatinine at 1st year $(n=51)^{\star}$ & 10 & 9 & $\mathrm{NS}$ \\
$\quad \leq 1.2 \mathrm{mg} / \mathrm{dL}$ & 20 & 12 & \\
$\quad>1.2 \mathrm{mg} / \mathrm{dL}$ \\
Ureteral complications $(n=55)$ & & & \\
$\quad$ No & 31 & 21 & $\mathrm{NS}$ \\
$\quad$ Yes & 3 (fistulae) & - & \\
\hline
\end{tabular}

AR, acute rejection.

${ }^{*}$ Cases with more than 1 year of follow-up only.

${ }^{\dagger} P=.052$.

tion. These findings are similar to those in routine renal biopsies. However, we did not observe a significant relation between the nature of the lesions encountered on the ureteral biopsies and the evolution of the transplant, namely the occurrence of ureteral complications. A longer follow-up may help to define the significance of these findings.

\section{REFERENCES}

1. Katz JP, Greenstein SM, Hakki A, et al: Transitional epithelial lesions of the ureter in renal transplant rejection. Transplantation 45:710, 1988

2. Maier U, Madersbacher S, Falger SB, et al: Late ureteral obstruction after kidney transplantation: fibrotic answer to previous rejection? Transpl Int 10:65, 1997

3. Figueiredo AJ, Parada BA, Cunha MFX, et al: Ureteral complications: analysis of risk factors in 1000 renal transplants. Transplant Proc 35:1087, 2003

4. Racusen LC, Solez K, Colvin RB, et al: The Banff 97 working classification of renal allograft pathology. Kidney Int 55:713, 1999

5. Kuusanmäki P, Halttunen J, Paavonen T, et al: Acute rejection of porcine small bowel allograft: an extended histological scoring system. Transplantation 58:757, 1994

6. Demetris AJ, Batts KP, Dhillon AP, et al: Banff schema for grading liver allograft rejection: an international consensus document. Hepatology 25:658, 1997

7. Rush DN, Henry SF, Jeffery JR, et al: Histological findings in early routine biopsies of stable renal allograft recipients. Transplantation 57:208, 1994

8. Veronese FV, Gonçalves LF, Edelweiss MI, et al: Interpretation of surveillance kidney allograft biopsies according to the Banff criteria. Transplant Proc 31:3019, 1999

9. Veronese FV, Noronha IL, Manfro RC, et al: Protocol biopsies in renal transplant biopsies: three year follow-up. Transplant Proc 34:500, 2002

10. Nankivell BJ, Fenton-Lee CA, Kuypers DRJ, et al: Effect of histological damage on long-term kidney transplant outcome. Transplantation 71:515, 2001

11. Abo-Zenah H, Katsoudas S, Wild G, et al: Early human renal allograft fibrosis: cellular mediators. Nephron 91:112, 2002 